- Having a functioning natural dentition of more than 20 teeth is a reasonable threshold for acceptable oral health and a functional dentition into old age.

- Maintaining a healthy and functional dentition into old age may have an important additional role to play in maintaining a healthy Body Mass Index.

- The association of poor oral health with obesity is likely to be associated with the quality of the diet.

- Amongst adults over 65 years, having few or no natural teeth was associated with a greater risk both of being underweight and with a greater risk of being obese.

- There was no difference in BMI between edentulous people and dentate adults having a functioning dentition of more than 20 teeth.

\title{
The relationship between oral health status and Body Mass Index among older people: a national survey of older people in Great Britain
}

\author{
A. Sheiham, ${ }^{1}$ J.G. Steele, ${ }^{2}$ W. Marcenes, ${ }^{3}$ S. Finch ${ }^{4}$ and A.W.G. Walls ${ }^{5}$
}

Aims To assess the relationship between oral health status and Body Mass Index.

Material and methods This paper relates to the free-living sample (participants who lived in their own home, rather than an institution) of the National Diet and Nutrition Survey: people aged 65 years and older. Subjects 629 adults.

Data collection A probability random national sample of adults who had a dental examination, an interview and an anthropometric examination. Data analysis Fisher's exact test and multivariate logistic modeling. Findings Being underweight was relatively uncommon in this population. People without teeth were significantly $(P=0.05)$ more likely to be underweight than those with 11 or more teeth; $12.3 \%$ and $2.9 \%$. A highly statistically significant $(P=0.001)$ difference was observed in $B M I$ between dentate people with 1-10 teeth and with more than 10 teeth; $24 \%$ and 2.9\% were underweight. Dentate people with less than 21 natural teeth were on average more than 3 times more likely to be obese than those with 21-32 teeth $(P=0.036)$. There was no significant difference in both the proportion of overweight and obese adults between those who were edentulous and dentate with 21 or more teeth. A similar pattern was observed when the number of posterior occluding pairs was compared with BMI categories. Results of multiple logistic regression were adjusted for the confounding effects of age, social class, region of origin and partial denture wearing.

Conclusions Older people in Britain with more than 20 teeth are more likely to have a normal Body Mass Index.

Dental status can affect diet, nutrition and health by changes in the types of food eaten. ${ }^{1-3}$ Tooth loss has been associated with changes in food preference and nutritional deficiency. ${ }^{4,5}$ The evi-

\footnotetext{
${ }^{1 *}$ Professor of Dental Public Health, Department of Epidemiology and Public Health, University College London Medical School. ${ }^{2}$ Senior Lecturer in Restorative Dentistry, Department of Restorative Dentistry, University of Newcastle Dental School. ${ }^{3}$ Senior Lecturer in Epidemiology and Dental Public Health, Department of Epidemiology and Public Health, University College London Medical School ${ }^{4}$ Research Director, National Centre for Social Research, London. ${ }^{5}$ Professor of Restorative Dentistry, Department of Restorative Dentistry, University of Newcastle Dental School

*Correspondence to: Professor Aubrey Sheiham, Department of Epidemiology and Public Health, 1-19 Torrington Place, London WC1E 6BT

Email:a.sheiham@ucl.ac.uk
}

\section{Refereed paper}

Received 23.05.01; Accepted 18.01.02

๑ British Dental Journal 2002; 192: 703-706 dence that people whose mastication is impaired by tooth loss are more likely to be underweight is conflicting. In the 1967-1968 DHSS $^{6}$ study of elderly people in Britain, Berry found that inefficient mastication was associated with being underweight and leanness. They also had 20\% less energy intake. Further evidence for an association between edentulousness and under-nutrition comes from the British DHSS survey ${ }^{6}$ of nutrition and health in old age. Conversely, differences in body weight by dental status were not found by Elwood and Bates. ${ }^{7}$ Halling, Bengtsson and Avridsson, ${ }^{8}$ on the other hand, found that body weight was higher in edentulous people and in those with 1-15 teeth compared with those with more than 15 teeth. A similar trend was reported by Nowjack-Raymer ${ }^{9}$ in a large national survey in the USA.

Overall it appears that edentulousness and chewing problems are related to being underweight, ${ }^{10-12}$ but the true relationship is far from clear. Whilst relationships between dental state, chewing ability and food choice have been explored, these studies often suffer from being small scale, non-representative or insufficiently rigorous in the collection of nutritional data. There are only very limited data linking nutrition or general health with dental state. From the point of view both of public health and of individual healthcare it is important to understand any relationship between dental state and body weight if either are to be managed appropriately in the elderly.

This study aims to clarify the relationship between dental status and Body Mass Index (BMI), using data from the National Diet and Nutrition Survey of people 65 years and older.

\section{MATERIALS AND METHODS}

The National Diet and Nutrition Survey (NDNS) included two independent random samples of free-living and institutionalised adults aged 65 and over living in Great Britain. This paper relates to the free-living sample; participants who lived in their own home, rather than an institution.

The free-living sample was selected using a multi-stage random probability design. Households containing eligible adults were identified from the returns and a sample of individuals was selected using probabilities required to produce the target sample sizes. Institutions were excluded. Full details of the sampling procedures and the response rate are published elsewhere. ${ }^{2,13}$

The oral health survey of people participating in the NDNS was carried out to relate their oral health to their dietary intake and 
nutritional status; it included an oral examination and an oral health interview. ${ }^{2}$ Trained and calibrated dentists undertook the oral examinations, whilst trained interviewers conducted the oral health questionnaire. Two measures of oral health were derived to give an indication of the potential masticatory efficiency. They were the number of natural teeth and the number of posterior occluding pairs of teeth (POPs). The relationship between mechanical efficiency and the numbers of natural teeth and their distribution has been well established for many years, ${ }^{14}$ though the impact of a partial denture on mechanical function is less clear.

The dietary survey collected detailed information about the quantities of foods and nutrients consumed by the sample of elderly people as well as demographic data, anthropometric measurements and measurements of the levels of certain nutrients in blood and urine. To measure body fatness, height and weight, measurements were used to derive the Quetelet or Body Mass Index, a ratio between the weight in kilograms and the height in metres squared (weight $[\mathrm{kg}] /$ height $[\mathrm{m}]^{2}$. Height was measured with a portable, digital telescopic stadiometer with participants without shoes and head horizontal in the Frankfurt Plane. Weight was measured to the nearest 100 grams using Soehnle Quantratonic digital personal scales on a hard, level surface. ${ }^{13}$ A ratio of 20 to 25 was considered as 'normal', while less than this defined underweight, values between 25 and 30 were defined as being overweight, and values of 30 or over were considered obese. Whilst these divisions are essentially arbitrary, they are widely used. ${ }^{14}$

\section{Data analysis}

Data analysis included descriptive and analytic statistics. Statistical significance was set at the 5\% level. Multivariate logistic modeling was used to make allowance for the potential confounding effects of age, sex, social class, region of origin and partial denture wearing during the assessment of the relationships tested. Due to the low prevalence of underweight elderly people ( $n=24$, Table 2), adjusted odds ratios could not be estimated using multivariate logistic modeling for this group, and Fisher's exact test was used. Since there was no difference between those with 11-20 and 21-32 teeth (2.9\% were underweight in both groups) these categories were combined for analysis of data on low body weight. Separate analyses were conducted to compare edentulous people with those with 11-32 teeth and to compare those with 1-10 teeth with the same groups. A similar approach was adopted when the relationship between number of POPs and BMI was analysed. The categories 1-4 and 5 or more were combined and separate analyses were conducted to compare with those dentate people with zero POPs and the edentulous. This was necessary because Fisher's exact test applies only to a two by two table.

\begin{tabular}{|c|c|c|}
\hline & Frequency & Percent \\
\hline \multicolumn{3}{|l|}{ Sex } \\
\hline Female & 349 & 55.5 \\
\hline Male & 280 & 44.5 \\
\hline \multicolumn{3}{|l|}{ Age } \\
\hline 65-74 years old & 292 & 46.4 \\
\hline $75-84$ years old & 243 & 38.6 \\
\hline $85+$ years old & 94 & 14.9 \\
\hline \multicolumn{3}{|l|}{ Region of residence } \\
\hline North England and Scotland & 199 & 31.6 \\
\hline Midlands and Wales & 268 & 42.6 \\
\hline South England & 162 & 25.8 \\
\hline \multicolumn{3}{|l|}{ Social class } \\
\hline Manual & 327 & 52.0 \\
\hline Non-manual & 302 & 48.0 \\
\hline Total & 629 & 100.0 \\
\hline
\end{tabular}

\begin{tabular}{|c|c|c|c|}
\hline \multirow[b]{2}{*}{ BMI } & \multirow[b]{2}{*}{ Total } & \multirow{2}{*}{$\begin{array}{c}\text { Dental status } \\
\text { Dentate }\end{array}$} & \multirow[b]{2}{*}{ Edentulous } \\
\hline & & & \\
\hline less than 20 & 24 (3.8\%) & $11(3.2 \%)$ & $13(4.6 \%)$ \\
\hline $20-25$ & $188(29.9 \%)$ & 95 (27.5\%) & 93 (32.9\%) \\
\hline $25-30$ & $298(47.4 \%)$ & $171(49.4 \%)$ & 127 (44.9\%) \\
\hline 30 and more & $119(18.9 \%)$ & 69 (19.9\%) & $50(17.7 \%)$ \\
\hline Total & 629 & 346 (55\%) & $283(45 \%)$ \\
\hline
\end{tabular}

\section{RESULTS}

Complete data were available for 629 people. The frequency distribution of demographic variables is presented in Table 1. A total of 346 (55\%) participants were dentate and 283 (45\%) were edentulous (Table 2).

A scatterplot of number of teeth against BMI showed that the relationship was not linear. BMI data were categorized into underweight $(\mathrm{BMI}<20)$, overweight $(25-30)$ and obese $(>30)$ and were compared with 'normal' (20-25). The majority of the sample had a BMI greater than 25; 47.4\% were overweight and 18.9\% were obese. Few people were underweight (3.8\%), and 29.9\% were in the 'normal' category. The frequency distribution of BMI categories was similar in dentate and edentulous people (Table 2).

The results of Fisher's exact test to evaluate the relationship between being underweight and dental status showed that people without teeth were significantly $(\mathrm{P}=0.05)$ more likely to be underweight than those with 11 or more teeth, $12.3 \%$ and $2.9 \%$ respectively (Table 3 ). There was also a highly statistically significant $(\mathrm{P}=0.001)$ difference in $\mathrm{BMI}$ between dentate people with 1-10 teeth and those with more than 10 teeth; 24\% and 2.9\% were underweight respectively (Table 3). The results of multiple logistic regression demonstrated that dentate people with less than 21 natural teeth were on average more than three times more likely to be obese than those with 21-32 teeth $(\mathrm{P}=0.036$, Table 3$)$. There was no statistical difference in both the proportion of overweight and obese adults between those who were edentulous and dentate with 21 or more teeth. A similar pattern was observed when the POPs measure of oral health was used (Table 4). All results of multiple logistic regression were adjusted for the confounding effects of age, social class, region of origin and partial denture wearing.

\section{DISCUSSION}

This research reports data on a carefully drawn national probability sample. Validated measures were used, data collection was rigorous, and data analysis took into account the confounding effects of age, social class, region of origin and partial denture wearing during the assessment of the relationships tested. The analysis was deliberately restricted to the relationship between BMI and the presence and number of natural teeth. The functional benefits and wearing habits of complete dentures are variable and difficult to quantify, particularly in the absence of a reasonable population of 'non-wearers'. All but a very small number of individuals without any natural teeth in one or both arches had complete dentures and wore them for some part of the day. The presence of partial dentures in those with some natural teeth was included as a co-variable in the model so that the impact of partial dentures could be accounted for when evaluating the relationship between BMI and the number of natural teeth.

The results of this study showed that having a functioning natural dentition, defined as having more than 20 teeth, increased the likelihood of having a 'normal' BMI (20-25). Amongst adults over 65 years, having few natural teeth or none at all was associated with a greater risk both of being underweight and with a greater risk of being obese. The approach used 
in this study tested the relationship between oral health measures and four categories of BMI, underweight, 'normal', overweight and obese, as it was clear that the association between number of teeth and BMI was not linear. This differs from other studies that assumed a linear association between oral health measures and relative body weight. To assume linearity may cancel or mask the true association, or alternatively, may show a weak association in either direction. Existing evidence relating edentulousness, and having few teeth, to being underweight, ${ }^{10-12}$ overweight ${ }^{8}$ or unrelated to weight appear to be contradictory. ${ }^{7}$ These findings may now explain the apparent contradictions.

Interestingly, there was not a statistically significant difference in BMI between edentulous people and dentate adults having a functioning dentition of more than 20 teeth. The insufficient masticators identified in this study were those with less than 21 teeth without replacement. This explains the lack of a significant association between dental status and BMI reported in Table 2.
Numbers of teeth may not be an adequate measure of masticatory function. Having premolar and molar teeth which occlude are relevant too. This study tested relationship between BMI and number of ocluding posterior pairs, and the results followed the same pattern observed when the number of teeth were used as a measure of oral health (Table 4).

The nature of the relationship between BMI and oral health is clearly rather complex. A low BMI is easily explainable on the basis of there being real functional difficulties that can prevent normal eating in some cases. On the other hand, the association of poor oral health with obesity is likely to be associated with the quality of the diet. There may even be an argument that the loss of teeth may have been the result of a poor quality diet in some instances. Interestingly, the strongest associations between BMI (both being underweight and obese) were where people had some teeth, but were not edentulous. It can be more difficult to provide adequate function, and therefore to provide for an adequate and varied diet, where there are a few poorly distributed teeth than

\begin{tabular}{|c|c|c|c|c|}
\hline Number of teeth & $\mathrm{N}(\%)$ & & OR (95\% CI) & Pvalue \\
\hline edentulous & $\begin{array}{l}\mathrm{BMI}<20 \\
13(12.3 \%)\end{array}$ & $\begin{array}{l}\mathrm{BMI}=20-25 \\
93(87.7 \%)\end{array}$ & & \\
\hline $11-32$ & $2(2.9 \%)$ & $67(97.1 \%)$ & & $0.050^{1}$ \\
\hline $1-10$ & $9(24.3 \%)$ & 28 (75.7\%) & & \\
\hline \multirow[t]{2}{*}{$11-32$} & $2(2.9 \%)$ & 67 (97.1\%) & & $0.001^{1}$ \\
\hline & $\mathrm{BMI}=25-30$ & $\mathrm{BMI}=20-25$ & & \\
\hline edentulous & 127 (57.7\%) & 93 (42.3\%) & $1.2(0.54,2.51)$ & $0.703^{2}$ \\
\hline $1-10$ & $53(65.4 \%)$ & 28 (34.6\%) & $1.7(0.76,3.91)$ & 0.195 \\
\hline $11-20$ & 74 (69.2\%) & $33(30.8 \%)$ & $1.9(0.94,3.69)$ & 0.074 \\
\hline \multirow[t]{2}{*}{$21-32$} & 44 (56.4\%) & 34 (43.6\%) & 1 & \\
\hline & $\mathrm{BMI}>30$ & $\mathrm{BMI}=20-25$ & & \\
\hline edentulous & $50(35.0 \%)$ & 93 (65.0\%) & $2.3(0.78,6.77)$ & $0.129^{2}$ \\
\hline $1-10$ & $23(45.1 \%)$ & $28(54.9 \%)$ & $3.1(1.08,8.84)$ & 0.036 \\
\hline $11-20$ & $32(49.2 \%)$ & $33(50.8 \%)$ & $3.3(1.29,8.22)$ & 0.012 \\
\hline 21-32 & 14 (29.2\%) & 34 (70.8\%) & 1 & \\
\hline
\end{tabular}

Table 4: Frequency distribution of body mass index by number of posterior occlusal pairs (POPs) and odds ratio adjusted for age, sex, social class, region of residence and partial denture wearing; in a sample of 629 free-living adults aged 65 or over in Great Britain (unweighted data).

\begin{tabular}{|c|c|c|c|c|}
\hline POPs & BMI: N (\%) & & OR (95\% Cl) & $p$ value \\
\hline $\begin{array}{l}\text { edentulous } \\
1+\end{array}$ & $\begin{array}{l}\mathrm{BMI}<20 \\
13(12.3 \%) \\
3(4.6 \%)\end{array}$ & $\begin{array}{l}\mathrm{BMI}=20-25 \\
93(87.7 \%) \\
62(95.4 \%)\end{array}$ & & $0.111^{1}$ \\
\hline $\begin{array}{l}0 \\
1+\end{array}$ & $\begin{array}{l}8(19.5 \%) \\
3(4.6 \%)\end{array}$ & $\begin{array}{l}33(80.5 \%) \\
62(95.4 \%)\end{array}$ & & $0.021^{1}$ \\
\hline $\begin{array}{l}\text { edentulous } \\
0 \\
1-4 \\
5+\end{array}$ & $\begin{array}{l}\mathrm{BMI}=25-30 \\
127(57.7 \%) \\
70(68.0 \%) \\
59(63.4 \%) \\
42(60.0 \%)\end{array}$ & $\begin{array}{l}\mathrm{BMI}=20-25 \\
93(42.3 \%) \\
33(32.0 \%) \\
34(36.6 \%) \\
28(40.0 \%)\end{array}$ & $\begin{array}{c}0.93(0.42,2.06) \\
1.5(0.67,3.32) \\
1.2(0.61,2.49) \\
1\end{array}$ & $\begin{array}{l}0.864^{2} \\
0.327 \\
0.554\end{array}$ \\
\hline $\begin{array}{l}\text { edentulous } \\
0 \\
1-4 \\
5+\end{array}$ & $\begin{array}{l}\mathrm{BMI}>30 \\
50(35.0 \%) \\
31(48.4 \%) \\
25(42.4 \%) \\
13(31.7 \%)\end{array}$ & $\begin{array}{l}\mathrm{BMI}=20-25 \\
93(65.0 \%) \\
33(51.6 \%) \\
34(57.6 \%) \\
28(68.3 \%)\end{array}$ & $\begin{array}{c}1.7(0.61,4.95) \\
2.7(1.0,7.32) \\
1.8(0.74,4.51) \\
1\end{array}$ & $\begin{array}{l}0.305^{2} \\
0.049 \\
0.191\end{array}$ \\
\hline
\end{tabular}


where there are none at all. This is a problem particularly where the teeth are in only the upper arch. Whilst this does not always hold true it may partly explain the relationships observed.

The findings of this study have important implications for public health policy. Previous analyses of these data have shown that people with fewer than 20 teeth had dietary restrictions ${ }^{3}$ and nutritional deficiency ${ }^{5}$ when compared with those with 20 or more teeth. The findings reported here provide further scientific evidence for 20 or more natural teeth being a reasonable threshold for acceptable oral health and a functional dentition into old age. ${ }^{16-18}$

In conclusion, maintaining a healthy and functional dentition into old age may have an important additional role to play in maintaining a healthy Body Mass Index.

The National Diet and Nutrition Survey of people aged 65 years and over was funded jointly by the Ministry of Agriculture, Fisheries and Food and the Department of Health and conducted by SCPR. MAFF's responsibility for the NDNS programme transferred to the Food Standards Agency on its establishment in April 2000. The views expressed in this article are not necessarily those of $\mathrm{DoH}$ or the Food Standards Agency.

1. Posner B M, Jette A, Smigelski C, Miller D, Mitchell P. Nutritional risk in New England elders. J Gerontol 1994:49:123-132

2. Steele J G, Sheiham A, Marcenes W, Walls A W G. National diet and Nutrition Survey: people aged 65 years and over. Volume 2: Report of the oral health survey. London: TSO, 1998.

3. Sheiham A, Steele J G, Marcenes W, Finch S, Walls A W G. The impact of oral health on stated ability to eat certain foods; findings from the National Diet and Nutrition Survey of older people in Great Britain Geriodontology 1999; 16: 11-20.

4. Carlos JP. Wolfe M D. Methodological and nutritional issues in assessing oral health of aged subjects. Am J Clin Nutr 1989; 50: 1210-1218.

5. Sheiham A, Steele J G, Marcenes W, et al. The relationship among dental status, nutrient intake, and nutritional status in older people. J Dent Res 2001: $80: 408-413$.

6. DHSS. Report on health and social subjects No 3. A nutrition survey of the elderly. London: HMSO, 1979.

7. Elwood P C, Bates J F. Dentition and nutrition. Dent Pract 1972; 22: 427-429.

8. Halling A, Bengtsson C, Avridsson L R. Diet in relation to number of remaining teeth in a population of middle-aged women in Gothenburg, Sweden. Swed Dent J 1988; 12: $39-45$

9. Nowjack-Raymer R E. The impact of dental status on diet nutrition and nutritional status in USA adults. PhD thesis, University of London, 2000.

10. Fischer J, Johnson M A. Low body weight and weight loss in the aged. J Am Diet Assoc 1990; 90: 1697-1706.

11. Keller H H. Malnutrition in institutionalized elderly: how and why? J Am Geriatr Soc 1993: 41: 1212-1218.

12. Sullivan D H. The role of nutrition in increased morbidity and mortality. Clin Geriatr Med 1995; 11:661-674.

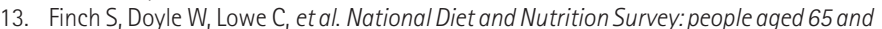
over. Vol. 1: Report of the diet and nutrition survey. London: TSO, 1998.

14. Bates J F, Stafford G D, Harrison A. Masticatory function: a review of the literature III. Masticatory efficiency. J Oral Rehab 1976; 3: 57-67.

15. Willett W. Anthroprometric measures and body composition. In: Willett W. (ed) Nutrition epidemiology, 2nd ed. Oxford, Oxford University Press, 1998, pp. 244-272.

16. Kayser A F. Shortened dental arches and oral function. J Oral Rehabil 1981: 8: 457462.

17. WHO. A review of current recommendations for the organization and administation of community oral health services in Northern and Western Europe. Report of a WHO Workshop. Copenhagen: WHO, 1982.

18. DoH. An Oral Health Strategy for England. London: Department of Health, 1994. 